Supplement of Clim. Past, 16, 503-522, 2020

https://doi.org/10.5194/cp-16-503-2020-supplement

(C) Author(s) 2020. This work is distributed under

the Creative Commons Attribution 4.0 License.

(c) (1)

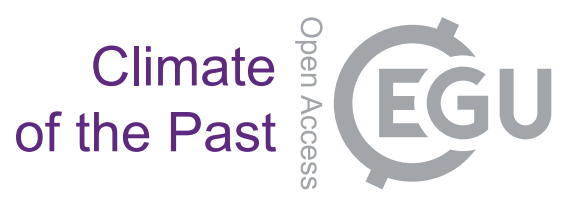

Supplement of

\title{
Estimation of gas record alteration in very low-accumulation ice cores
}

Kévin Fourteau et al.

Correspondence to: Kévin Fourteau (kevin.fourteau@univ-grenoble-alpes.fr)

and Patricia Martinerie (patricia.martinerie@univ-grenoble-alpes.fr)

The copyright of individual parts of the supplement might differ from the CC BY 4.0 License. 


\section{S1 Deconvolving the NEEM CFA record}

In the main paper we use high-resolution methane records as input atmospheric scenarios to study the smoothing of lowaccumulation records. However, high-accumulation records can only be used in such a way if the fast variability is well preserved and not affected by smoothing. In the case of NEEM, this appears not to be the case. It can be seen in Figure S1 that 5 it is not possible to find an age distribution to transform the NEEM record into the DO21 Vostok record. In particular, it is not possible to reproduce the Vostok record during the first feature of the DO21 event (1260 m depth in the record), as the methane peak is not high enough in the NEEM record. It means that in this case, NEEM cannot be directly used as the input atmospheric scenario. This suggests that the NEEM scenario needs to be deconvoluted first, to retrieve the full atmospheric variabilty.

To do this, one needs to assume an age distribution for the NEEM methane record. During the DO21 period, the NEEM

10 accumulation has been estimated to be between 10.4 and $13 \mathrm{~cm} \mathrm{yr}^{-1}$ ice equivalent, with an average value of $11.3 \mathrm{~cm} \mathrm{yr}^{-1}$ ice equivalent (Rasmussen et al., 2013). We therefore chose to use the age distribution estimated at the modern site of Siple Dome (10.8 $\mathrm{cm} \mathrm{yr}^{-1}$ ice equivalent, Witrant et al., 2012). In order to test the sensitivity of the results to the choice of GAD, we also performed the deconvolution with the age distribution of South Pole $\left(8.0 \mathrm{~cm} \mathrm{yr}^{-1}\right.$ ice equivalent $)$ and Berkner Island (14.1 $\mathrm{cm} \mathrm{yr}^{-1}$ ice equivalent, Witrant et al., 2012). The three deconvolutions produce the atmospheric scenarios displayed as solid lines in Figure S2. When these three scenarios are smoothed by the glacial age distribution chosen in Section 3.4.2 of the main paper, they result in similar gas records, displayed as dashed lines in Figure S2. We also performed the gas age distribution extraction procedure of Section 3.4.1 of the main paper, and found similar gas age distributions (within the uncertainty range) using the three deconvolutions as atmospheric references. It indicates that our results only weakly depend on the particular choice of GAD for the deconvolution of the NEEM record.

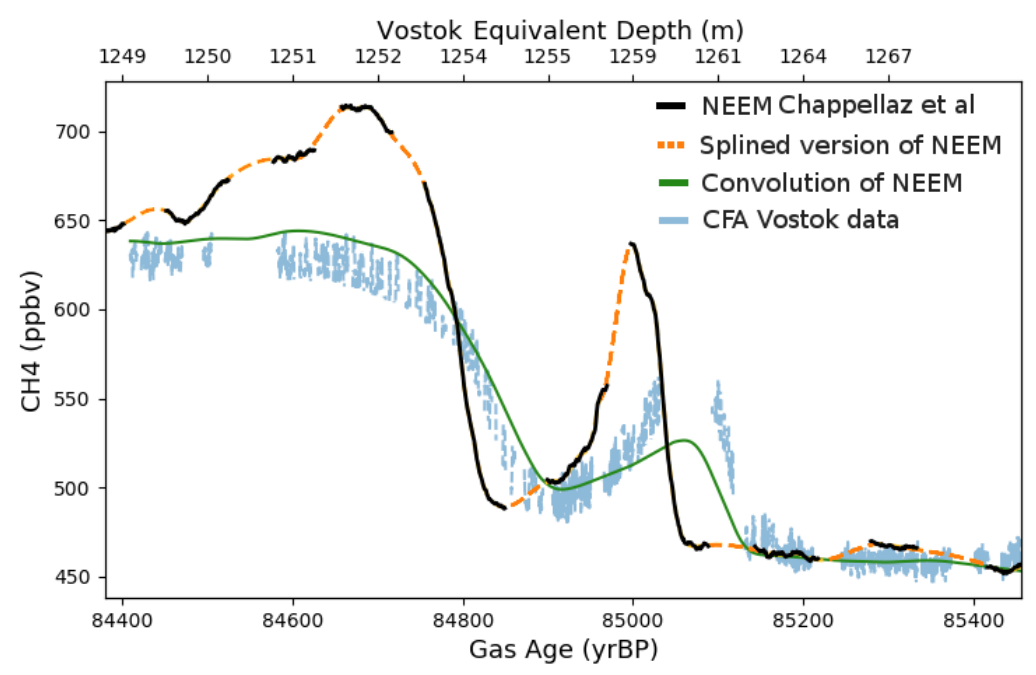

Figure S1. Illustration of the failure in finding a gas age distribution that smooths the atmospheric scenario (in dashed orange, splined NEEM data without deconvolution) in order to match the Vostok CFA measurements (in light blue). The smoothed version in green underestimates the fast event measured in the ice core around the $1260 \mathrm{~m}$ depth. The black line represents the original Chappellaz et al. (2013) data, that partially overlaps the spline.

\section{S2 Zoom over layering artifacts}

A closer look at the layering artifacts of the DO6-9 Dome C section is shown in Figure S3. This highlights the structure of the layering artifacts, and their widths of a couple of centimeters. They are similar to the artifacts reported in Figure 1 of Fourteau et al. (2017). 


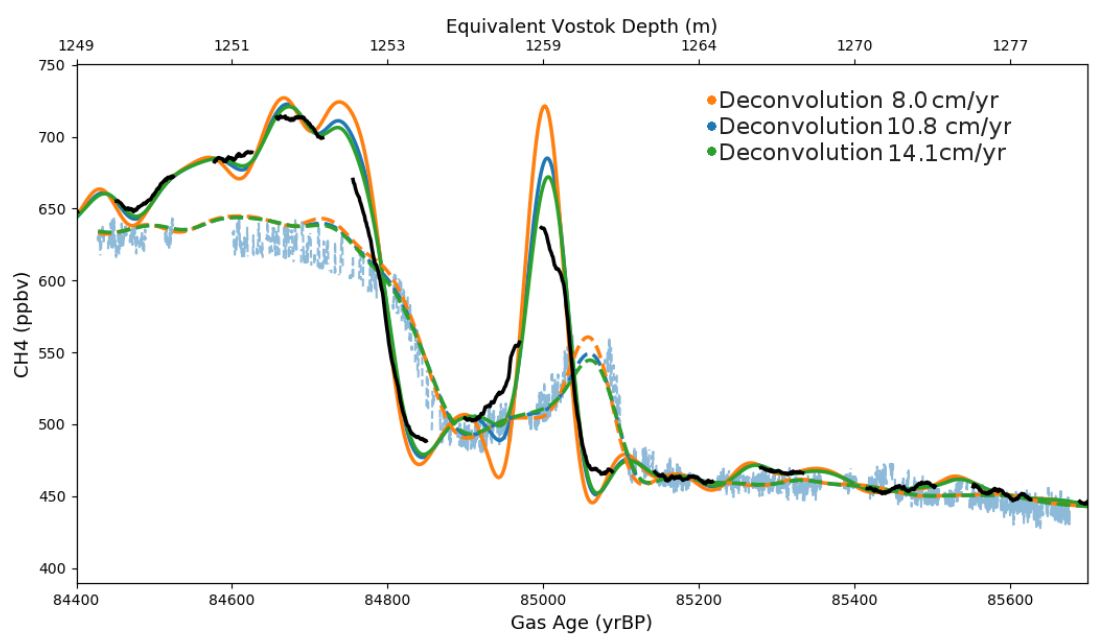

Figure S2. The NEEM deconvoluted scenarios and their convolution into Vostok records. For each color, the solid line represents the deconvoluted atmospheric reference and the dashed line represents the atmospheric reference smoothed by an East Antarctica glacial age distribution. Orange, blue and green curves respectively represent the cases with a 8.0,10.8, and $14.1 \mathrm{~cm} \mathrm{yr}^{-1}$ ice equivalent accumulation for the NEEM gas age distribution during the DO21 period. The original NEEM data are also shown in black.

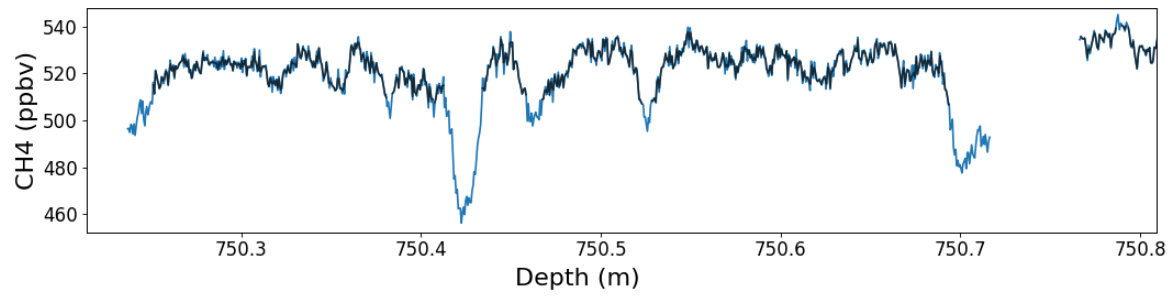

Figure S3. Zoom over the DO6-9 Dome C methane record. The blue data are the raw CFA measurements. In black are the data cleaned for layering artifacts with the recursive cleaning procedure presented in Section 3.3.3 of the main paper.

\section{S3 Uncertainty in Gas Age Distributions}

The extraction method yields an optimal GAD that minimizes the root-mean-square Deviation (RMSD) between the CFA measurements and the smoothed atmospheric reference. To quantify the uncertainties associated with the calculated GADs, we performed a dedicated analysis. For each of the five ice core sections, we studied the impact of choosing slightly modified

5 location and scale parameters.

Practically, we modify the scale and location parameters of the log-normal law (equation provided in Table 2 of the main paper) until the resulting RMSD is $15 \%$ larger than its optimal value. The locations and scales were modified following straight lines in the \{location, scale\} space, starting from the optimal values (Figure S4). We then obtained a set of 10 GADs meant to represent the limit of acceptable distributions. These GADs and their corresponding smoothed methane records in the ice are displayed in Figures S5 to S9. In the right panel of these figures, we also represented the set of location and scale values that increase the RMSD by $15 \%$. The regions enclosed by the those values can be viewed as the uncertainty ranges of the location and scale parameters. However, one should note that it does not entail the potential bias of assuming log-normal functions for the age distributions. 
To visualize the uncertainty associated with the Dome $\mathrm{C}$ and Vostok glacial GADs, we plotted their uncertainty ranges in Figure S10. It confirms that the DO6-9 Dome C age distribution is less well constrained than Vostok GAD.

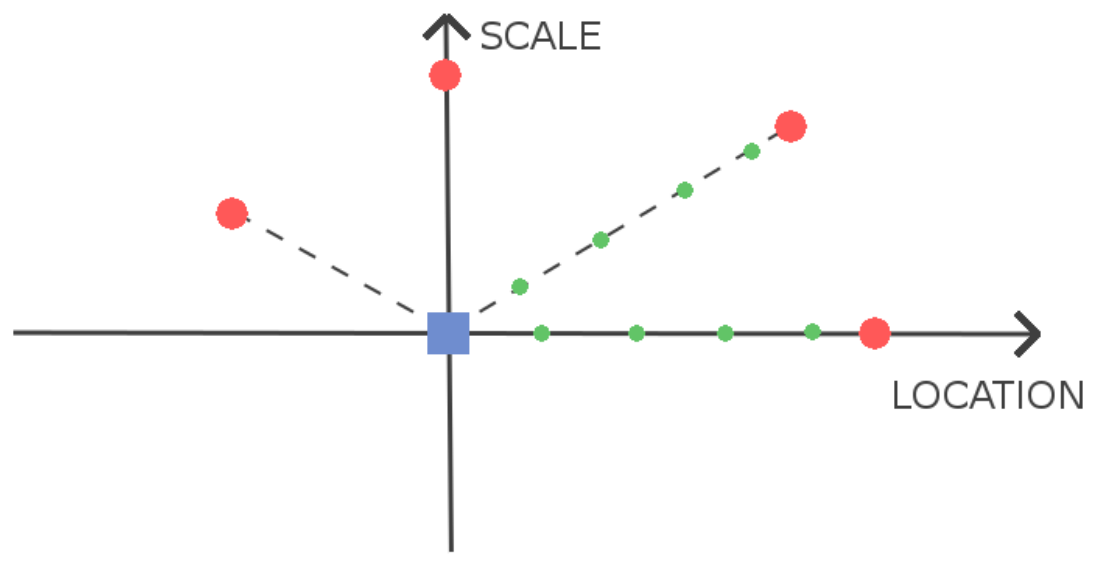

Figure S4. Method used to modify the location and scale parameters for the uncertainty assessment. Starting from the optimal values (blue square), the location and scale parameters are moved away following straight lines (dashed lines). If the new RMSD differs by less than 15\% with the optimal value (green dots) the location and scale are further modified, until the $15 \%$ are reached (red dots). Then the parameters are modified following a new line. In total 10 different lines are tested.
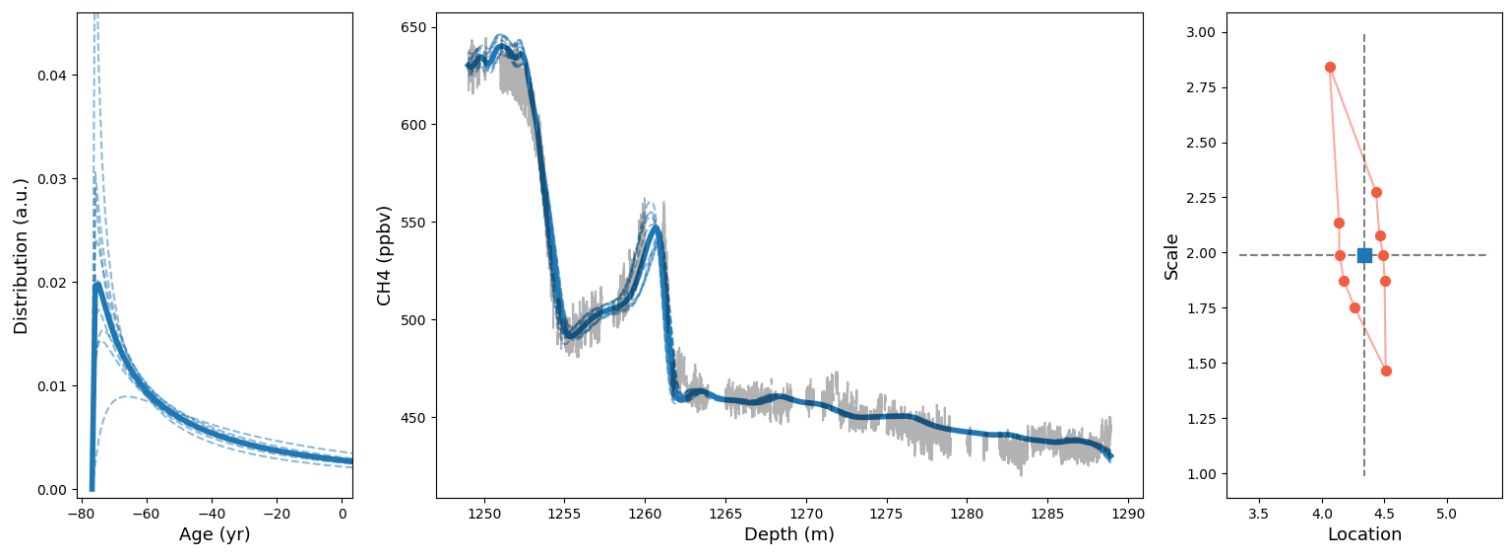

Figure S5. GAD for the DO21 event in Vostok. Left panel: Optimal gas age distribution as a bold solid line. Age distributions resulting in $15 \%$ RMSD increases are shown as dashed lines. Middle panel: smoothed methane record using the optimal GAD as a bold solid line, and smoothed methane records using the $15 \%$ higher RMSD distributions are displayed as dashed lines. CFA measurements are displayed in gray. Right panel: Location and scale parameters defining the gas age distributions. The blue square marks the optimal parameters and the red dots represent age distributions resulting in a $15 \%$ increase of RMSD. 

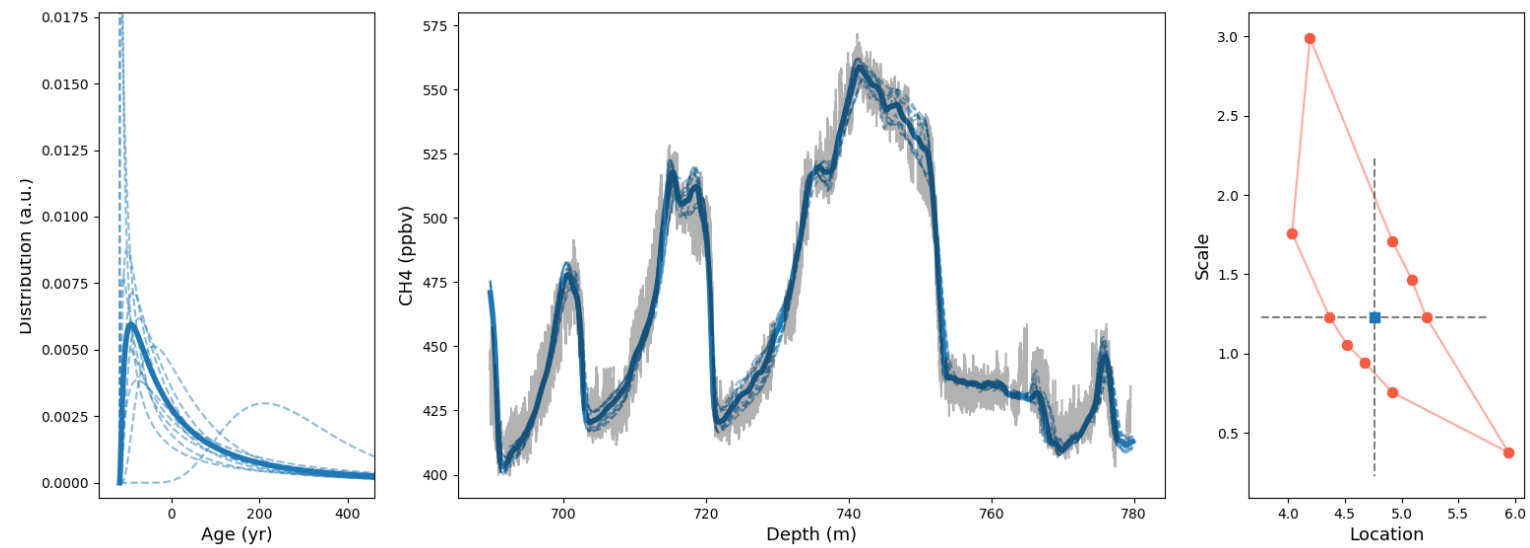

Figure S6. Same as Figure S5 for DO6-9 events in Dome C.
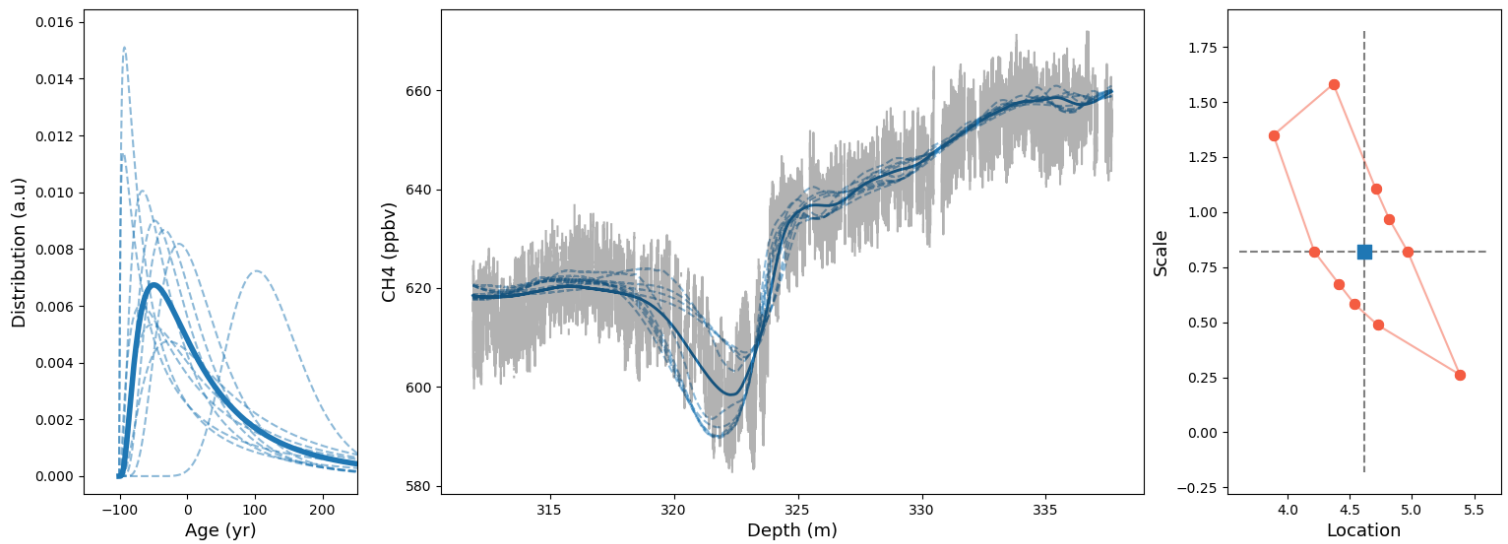

Figure S7. Same as Figure S5 for 8.2ka event in Dome C. 

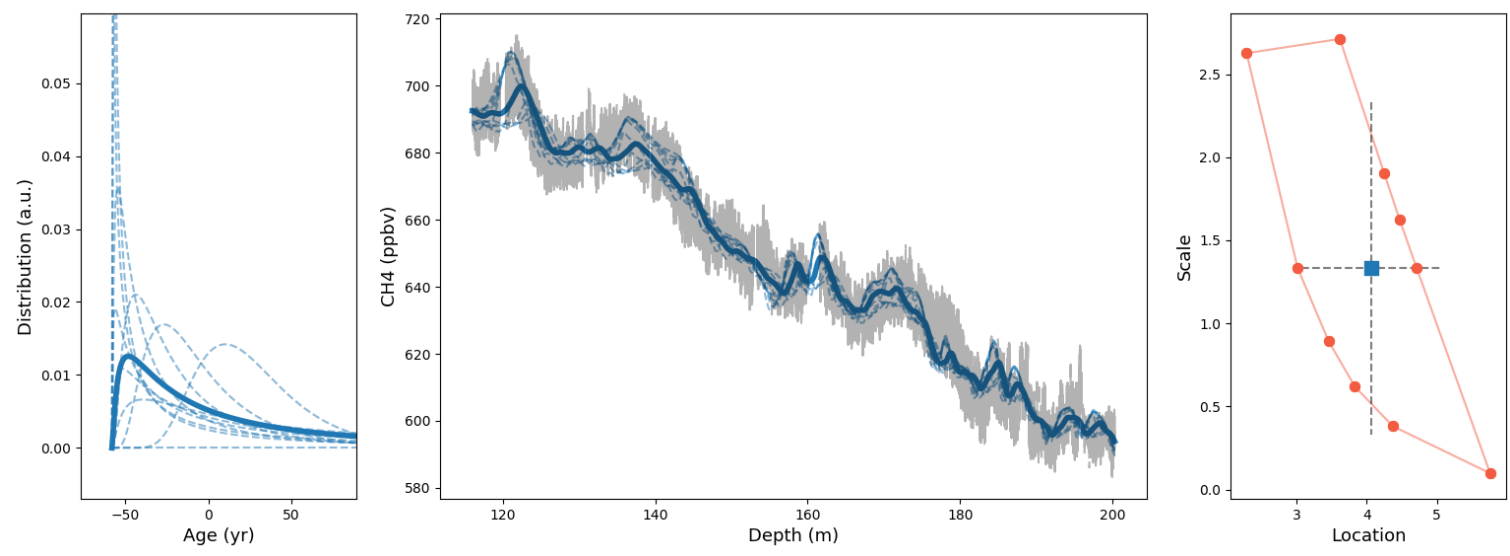

Figure S8. Same as Figure S5 for the modern section of Lock-In.
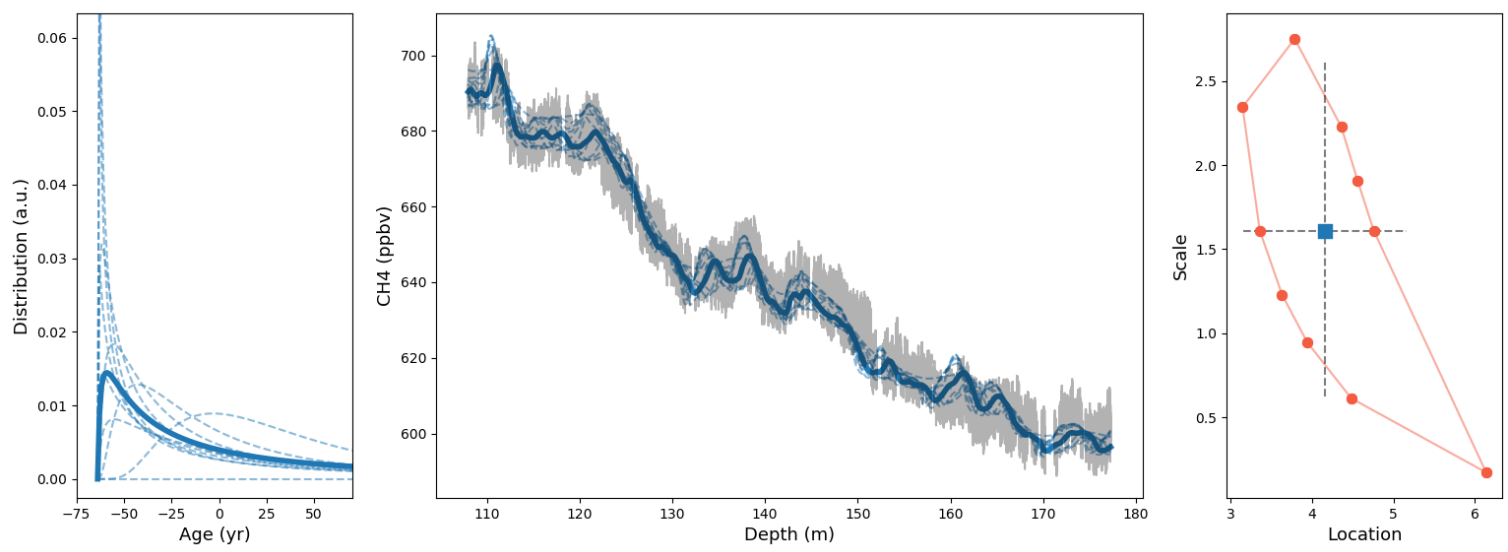

Figure S9. Same as Figure S5 for the modern section of Dome C. 


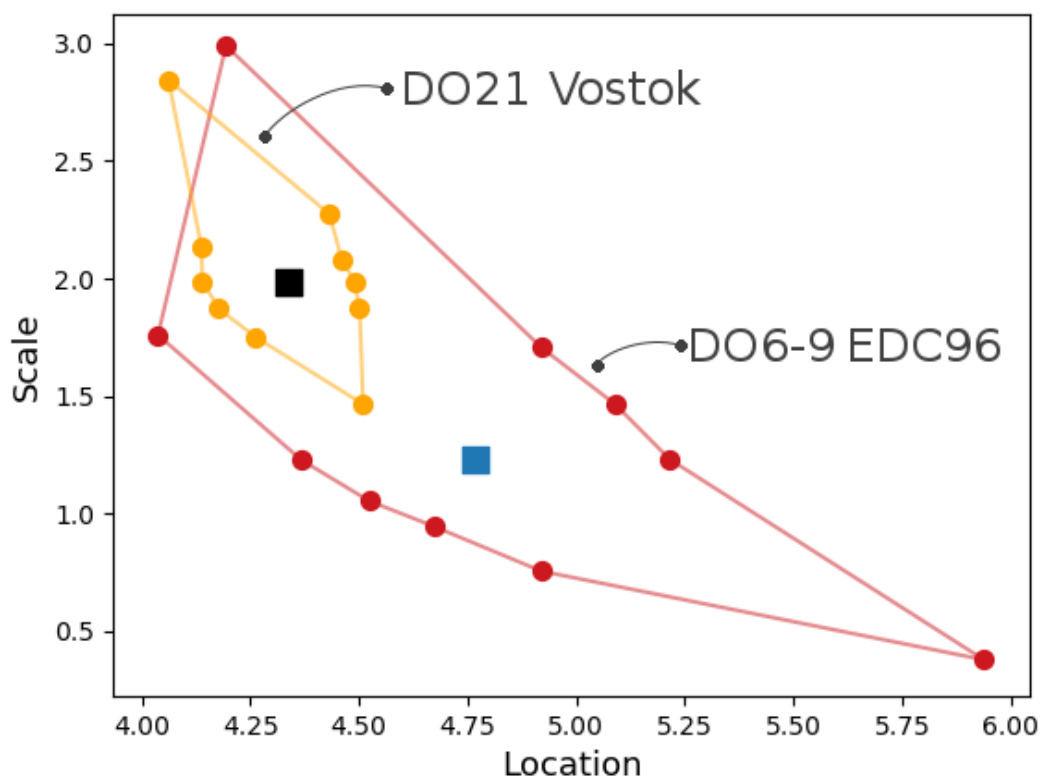

Figure S10. Uncertainty range of the location and scale parameters for the DO6-9 EDC96 (Dome C) and DO21 Vostok GADs. The DO6-9 Dome $\mathrm{C}$ uncertainty range is represented as red dots, and the optimal DO6-9 Dome C parameters are marked as a blue square. The DO21 Vostok uncertainty range is represented as orange dots, and the optimal DO21 Vostok parameters are marked as a black square. 


\section{References}

Chappellaz, J., Stowasser, C., Blunier, T., Baslev-Clausen, D., Brook, E. J., Dallmayr, R., Faïn, X., Lee, J. E., Mitchell, L. E., Pascual, O., Romanini, D., Rosen, J., and Schüpbach, S.: High-resolution glacial and deglacial record of atmospheric methane by continuous-flow and laser spectrometer analysis along the NEEM ice core, Clim. Past, 9, 2579-2593, doi:10.5194/cp-9-2579-2013, 2013.

5 Fourteau, K., Faïn, X., Martinerie, P., Landais, A., Ekaykin, A. A., Lipenkov, V. Y., and Chappellaz, J.: Analytical constraints on layered gas trapping and smoothing of atmospheric variability in ice under low-accumulation conditions, Clim. Past, 13, 1815-1830, doi:10.5194/cp13-1815-2017, 2017.

Loulergue, L., Schilt, A., Spahni, R., Masson-Delmotte, V., Blunier, T., Lemieux, B., Barnola, J.-M., Raynaud, D., Stocker, T. F., and Chappellaz, J.: Orbital and millennial-scale features of atmospheric $\mathrm{CH}_{4}$ over the past 800,000 years, Nature, 453, 383-386, doi:10.1038/nature06950, 2008.

Rasmussen, S. O., Abbott, P. M., Blunier, T., Bourne, A. J., Brook, E., Buchardt, S. L., Buizert, C., Chappellaz, J., Clausen, H. B., Cook, E., Dahl-Jensen, D., Davies, S. M., Guillevic, M., Kipfstuhl, S., Laepple, T., Seierstad, I. K., Severinghaus, J. P., Steffensen, J. P., Stowasser, C., Svensson, A., Vallelonga, P., Vinther, B. M., Wilhelms, F., and Winstrup, M.: A first chronology for the North Greenland Eemian Ice Drilling (NEEM) ice core, Clim. Past, 9, 2713-2730, doi:10.5194/cp-9-2713-2013, 2013.

15 Rhodes, R. H., Faïn, X., Stowasser, C., Blunier, T., Chappellaz, J., McConnell, J. R., Romanini, D., Mitchell, L. E., and Brook, E. J.: Continuous methane measurements from a late Holocene Greenland ice core: atmospheric and in-situ signals, Earth Planet. Sc. Lett., 368, 9-19, doi:10.1016/j.epsl.2013.02.034, 2013.

Witrant, E., Martinerie, P., Hogan, C., Laube, J. C., Kawamura, K., Capron, E., Montzka, S. A., Dlugokencky, E. J., Etheridge, D., Blunier, T., and Sturges, W. T.: A new multi-gas constrained model of trace gas non-homogeneous transport in firn: evaluation and behaviour at eleven polar sites, Atmos. Chem. Phys., 12, 11 465-11 483, doi:10.5194/acp-12-11465-2012, 2012. 